\title{
Consumidores y consumo de productos agroecológicos en los Integrantes de la Red de Mercados Agroecológicos de Bogotá, Región - RMABR
}

Consumers and consumption of agroecological products in the Members of the Network of Agroecological Markets of Bogotá, Region - RMABR

Consumidores e consumo de produtos agroecológicos nos integrantes da Rede de Mercados Agroecológicos de Bogotá, Região - RMABR

\section{Adriana-María Chaparro-Africano ${ }^{1}$ Luz-Magaly Franco-Chocue ${ }^{2}$}

Recibido: 23 de julio de 2019

Aprobado: 1 de abril de 2020

Publicado: 4 de mayo de 2020

Cómo citar este artículo:

Chaparro-Africano, A. M. y Franco-Chocue, L. M.. (2020). Consumidores y consumo de productos agroecológicos en los Integrantes de la Red de Mercados Agroecológicos de

Bogotá, Región - RMABR. Cooperativismo \& Desarrollo, 28(117), 1-36. doi: https://doi.org/10.16925/2382-4220.2020.02.04

Artículo de investigación. https://doi.org/10.16925/2382-4220.2020.02.04

1 Doctora en Recursos naturales y gestión sostenible, profesora titular programa de Ingeniería Agroecológica. Corporación Universitaria Minuto de Dios UNIMINUTO sede principal, Bogotá, Colombia.

Correo electrónico: achaparro@uniminuto.edu.co

ORCID: https://orcid.org/0000-0001-9124-3005

2 Programa de Ingeniería Agroecológica. Corporación Universitaria Minuto de Dios UNIMINUTO sede principal, Bogotá, Colombia.

Correo electrónico: Ifrancochoc@uniminuto.edu.co

ORCID: https://orcid.org/0000-0002-2415-7542 


\section{Resumen}

Los indicadores de sostenibilidad más deficientes en la Red de Mercados Agroecológicos de Bogotá, Región, para 2016 y 2017, fueron el número de consumidores y las ventas. Por lo anterior, esta investigación buscó caracterizar los consumidores y el consumo en la RMABR, para, luego, generar estrategias asertivas de comunicación, educación y de mercadeo.

Se realizó una investigación descriptiva, de enfoque mixto, para la cual se aplicó una encuesta con veinte seis preguntas a través de un formulario de Google, entre el 16 de abril y el 17 de mayo de 2018. La muestra total fue de 149 consumidores ( 80 \% confiabilidad, 5 \% de error). El análisis de los resultados se efectuó mediante estadística descriptiva y comparación con otros estudios.

La principal motivación de compra identificada es la salud, mientras la de no compra es el precio, aunque hay una disposición a pagar sobreprecio del $10 \%$. Los productos favoritos son cereales, frutas y verduras, las frecuencias preferidas de compra son semanal y quincenal, directamente a productores y en ferias, con un rango mayoritario de menos de 100 mil a 300 mil pesos. Estos estudios no son comunes en agroecología, se identificaron 16 estudios similares para productos ecológicos, pero uno solo para agroecológicos.

Palabras clave: Mercado agroecológico, consumidor agroecológico, consumo agroecológico, agroecología, consumo sostenible.

Códigos JEL: D12, Q13, Q01

\section{Abstract}

The weakest sustainability indicators in the Agroecological Markets Network of Bogotá, Region, for 2016 and 2017 , were the number of consumers and sales. Therefore, this research sought to characterize consumers and consumption in the RMABR, and then generate assertive communication, education and marketing strategies. A descriptive, mixed-focus investigation was carried out, for which a survey with twenty-six questions was applied through a Google form, between April 16 and May 17, 2018. The total sample was 149 consumers ( $80 \%$ reliability, $5 \%$ error). The analysis of the results was carried out using descriptive statistics and comparison with other studies.

The main motivation for purchasing identified is health, while the reason for not buying is price, although there is a willingness to pay a $10 \%$ premium. The favorite products are cereals, fruits and vegetables, the preferred purchase frequencies are weekly and fortnightly, directly from producers and at fairs, with a majority range of less than 100,000 to 300,000 pesos. These studies are not common in agroecology, 16 similar studies were identified for organic products, but only one for agroecological ones.

Key words: agro-ecological consumer, agro-ecological consumption, agro-ecology, sustainable consumption.

JEL codes: D12, Q13, Q01

\section{Resumo}

Os indicadores de sustentabilidade mais fracos da Rede de Mercados Agroecológicos de Bogotá, Região, para 2016 e 2017, foram o número de consumidores e vendas. Portanto, esta pesquisa buscou caracterizar consumidores e consumo na RMABR e gerar estratégias assertivas de comunicação, educação e marketing.

Foi realizada uma pesquisa descritiva, de foco misto, para a qual uma pesquisa com 26 perguntas foi aplicada através de um formulário do Google, entre 16 de abril e 17 de maio de 2018 . A amostra total foi de 149 con- 
sumidores ( $80 \%$ de confiabilidade, $5 \%$ de erro). A análise dos resultados foi realizada por meio de estatística descritiva e comparação com outros estudos.

A principal motivação para a compra identificada é a saúde, enquanto a razão para não comprar é o preço, embora exista uma disposição para pagar um prêmio de $10 \%$. Os produtos favoritos são cereais, frutas e vegetais, as frequências de compra preferidas são semanais e quinzenais, diretamente dos produtores e das feiras, com uma faixa maioritária de menos de 100.000 a 300.000 pesos. Esses estudos não são comuns em agroecologia, 16 estudos semelhantes foram identificados para produtos orgânicos, mas apenas um para produtos agroecológicos.

Palavras-chave: Mercado agroecológico, consumidor agroecológico, consumo agroecológico, agroecologia, consumo sustentável.

Códigos JEL: D12, Q13, Q01

\section{Introducción}

Los proyectos de formación, investigación y proyección social que vienen realizándose en el marco del proyecto Mercados Agroecológicos, del Semillero en Estudios Campesinos y Soberanía Alimentaria-SIECSA, del programa de Ingeniería de UNIMINUTO, sede Principal, incluyen a la Feria Agroecológica UNIMINUTO -liderado por una profesora-, el mercado ALaCena -liderado por graduados-, y Mercados Solidarios Minuto de Dios - proyecto de UNIMINUTO, Fundases y la Corporación Minuto de Dios-.

A raíz de la intención de crear ambientes de aprendizaje situados ${ }^{1}$ para los estudiantes de Ingeniería Agroecológica, y de la demanda de información en torno a mercadeo para productos agroecológicos, se decidió realizar estos proyectos desde el año 2012, 2013 y 2018, respectivamente. Con los beneficios adicionales de generar conocimiento y promover la agroecología y el consumo sostenible, pero dada la dimensión de la problemática en torno a la comercialización de productos agroecológicos, se decidió en 2015 establecer acercamiento con otros mercados agroecológicos, que cuentan con retos y con un potencial muy similares, con el fin de realizar gestiones colectivas que beneficien a las experiencias vinculadas.

La Red de Mercados Agroecológicos de Bogotá Región-RMABR se constituyó oficialmente, en 2016, gracias a la convocatoria de UNIMINUTO y a la concurrencia de varios mercados, que confiaron en que es una mejor opción cooperar que competir, para hacer sostenibles los mercados agroecológicos de la región. En la actualidad, la RMABR está compuesta por ocho mercados: Feria Agroecológica UNIMINUTO (FAU),

1 El aprendizaje situado visualiza la actividad en contexto como determinante en todo proceso de aprendizaje y ubica a la educación como parte indisoluble de la vida cotidiana (Sagástegui, 2004). 
ALaCena, La Canasta, Sembrando Confianza, Semilla Andina, Mercado Agroecológico Tierra Viva, Mercado Agroecológico Campesino y Agrosolidaria Engativá.

En la RMABR, se han priorizado varias áreas de gestión: investigación, formación, fortalecimiento integral de las experiencias, comunicación, resolución de conflictos e incidencia. UNIMINUTO SP lidera el área de investigación, y apoya las de resolución de conflictos y el Sistema Participativo de Garantías-SPG. Las cuales, a su vez, deben nutrir los procesos de fortalecimiento de los integrantes de la red, y lograr incidencia política y en la sociedad civil.

Durante 2016 y 2017, en la primera investigación realizada con la RMABR, se caracterizaron sus ocho integrantes y se diseñó una metodología de medición y análisis de indicadores de sostenibilidad para mercados agroecológicos, basada en MESMIS (Astier, Masera, y Galván - Miyoshi, 2008), esta metodología se aplicó a cuatro mercados en 2016 y a seis mercados en 2017 (Chaparro-Africano, 2019).

Unas de las principales deficiencias de los mercados, según la evaluación de indicadores de sostenibilidad 2017, son el número de consumidores - promedio 32 por semana, rango de 27 a 332-y las ventas totales - promedio anual \$123 251788 , rango de \$3 817086 y \$227 $483882-$, por lo que los promotores de dichos mercados manifestaron su deseo de hacer una investigación con el propósito de "caracterizar a los consumidores y al consumo de productos agroecológicos en los mercados de la RMABR, mediante la aplicación de una encuesta y el análisis de sus resultados", para, posteriormente, establecer un plan de mercadeo, que aporte a la sostenibilidad de los mercados agroecológicos.

A nivel de la RMABR y de otros mercados similares, el problema más relevante para su sostenibilidad es el consumo, lo que implica evaluar al número de familias e instituciones que participan como consumidores en los mercados, cuánto de lo que consumen es de origen agroecológico y cuáles son sus preferencias. Esta investigación permitió conocer de manera más amplia la diversidad de consumidores de la RMABR, los elementos que inciden en sus compras, así como las características y tendencias de consumo de productos agroecológicos, con el fin de generar propuestas de mejora a aplicar por cada mercado individualmente y por la RMABR en colectivo. Esto con el fin de llegar a un mayor número de consumidores, incrementar la proporción de productos agroecológicos que compra cada uno de ellos en estos mercados, aumentar la fidelización a los mismos, mejorar las ventas, y lograr una participación más activa en la RMABR, ya que finalmente, de estos logros depende en gran medida la sostenibilidad de los agroecosistemas que proveen a los mercados y de los mercados agroecológicos en sí. 
Este estudio se realizó porque unos de los indicadores de sostenibilidad más deficientes de la RMABR, para 2016 y 2017, fueron el número de consumidores y las ventas, de los cuales depende en gran medida la sostenibilidad de los mercados agroecológicos, la sostenibilidad de los cerca de 200 productores que los proveen. Estos últimos distribuidos mayoritariamente en Bogotá y municipios aledaños, así como la atención de cerca de 2000 familias e instituciones compradoras, ubicadas en Bogotá. Para corregir estos indicadores se considera necesario partir de la caracterización de los consumidores y del consumo, con el fin de, posteriormente, establecer estrategias asertivas de comunicación, educación y de mercadeo para el consumo sostenible.

La promoción que apoyaría esta investigación, de la producción y consumo agroecológicos en Bogotá y la región central de Colombia, es de gran importancia, dado que, a diciembre de 2018, solo se registran 19 operadores orgánicos en Bogotá y 14 en Cundinamarca (Ministerio de Agricultura y Desarrollo Rural, 2018), además, en cifras oficiales, la totalidad de los alimentos ecológicos colombianos es exportada (FIBL e IFOAM - Organics International, 2019).

\section{Elementos teóricos}

Los mercados agroecológicos son organizaciones formal o informalmente establecidas, que promueven la sostenibilidad de los sistemas agroalimentarios, mediante la distribución de productos agroecológicos en diversos circuitos cortos de comercialización, con la participación activa de productores, consumidores y promotores. La principal característica de estos mercados es su racionalidad alternativa en lo económico, social, ambiental y político, que determina grandes diferencias respecto a los mercados convencionales (Chaparro-Africano, 2019). Precisamente, los mercados agroecológicos son experiencias de economía solidaria porque no se basan únicamente en transacciones de interés material e individual, sino que en ellas prima el sentido cooperativo y de reciprocidad, como plantea Ávila-Romero (2018).

Dado que la agroecología, además de ser una práctica y una ciencia, es un movimiento social (Rosset y Martínez, 2016), y vincula no solo principios ecológicos y productivos, sino también planteamientos sociales, culturales y políticos, se decidió la creación de una red de mercados agroecológicos en Bogotá, con el fin de fortalecer a sus integrantes, a través de la creación colectiva y cooperada de conocimientos y prácticas, y a través de la incidencia en la sociedad civil y en el gobierno, para visibilizar y posicionar a los integrantes y a la red, en la distribución de alimentos ecológicos para la soberanía alimentaria, con el objetivo de que esta labor beneficie equitativamente a productores, consumidores y al resto de la naturaleza (RMABR, 2019). 
La agroecología busca alcanzar la sostenibilidad fuerte. Esta se refiere a la búsqueda del bienestar social que preserva los bienes comunes, a diferencia de la sostenibilidad débil y la intermedia, que consideran que los capitales económico, social y natural son sustituibles, total o parcialmente. Los principios planteados para la sostenibilidad fuerte incluyen: aumento de la eficiencia en el consumo de recursos; las tasas de aprovechamiento no deben exceder las tasas de regeneración y las emisiones de desechos no deben exceder la capacidad de asimilación renovable del medio ambiente; y los recursos no renovables deben ser explotados a una tasa igual a la creación de sustitutos renovables (Daly, 1991).

Precisamente, ante la intención de avanzar hacia la sostenibilidad fuerte, los mercados agroecológicos y la RMABR pretenden jalonar hacia atrás la producción agroecológica, y hacia adelante el consumo sostenible, convirtiéndose en dinamizadores que vinculan de manera alternativa la producción y el consumo, mediante acciones de resistencia, cooperación y movilización social (Chaparro y Calle, 2017).

Para mantener en el tiempo este esfuerzo dinamizador, se diseñó en 2016 un marco de indicadores de sostenibilidad, con el fin de seleccionar en colectivo las características deseables de los mercados agroecológicos, decidir el plan de trabajo anual, y hacer seguimiento al impacto que tuvieran las diferentes acciones desarrolladas por la RMABR, en dichos indicadores. Los doce indicadores, inmersos en cuatro atributos de sostenibilidad, son: productividad; estabilidad, resiliencia y confiabilidad; equidad, y autonomía, e incluyeron: ventas por productor, relación ingresos/costos del mercado, productores, consumidores, frecuencia, mercado local, producción agroecológica, distribución de beneficios, precios, participación, financiación y pedagogía (Chaparro-Africano, 2019).

Los productos agroecológicos son, según la definición del SPG de la RMABR, los alimentos frescos, procesados, productos para aseo personal, medicinales y cosméticos, Recuperados mediante un proceso holístico, que vincula las dimensiones ambiental, social y económica; que no emplean insumos externos nocivos para la salud humana o ambiental; que promueven la sostenibilidad de los agroecosistemas mediante la conservación y el uso sostenible de los bienes comunes; incluyentes de los saberes ancestrales y los nuevos conocimientos; centrados en procesos más que en insumos; y que fomentan el bienestar general de productores, consumidores y otros seres vivos (Chaparro y Naranjo, 2018).

Por su parte, por consumo responsable, se entiende a la reducción de los impactos negativos ambientales del consumo, pero también, al incremento de los impactos positivos, sociales y ambientales del consumo, envolviendo estos dos aspectos, un fuerte componente ético (Hinton y Godman, 2009). 
En esta investigación se entienden como diferentes la producción orgánica, ecológica y biológica, sinónimos según la Resolución 187 de 2006 del Ministerio de Agricultura y Desarrollo Rural (MADR), y la producción agroecológica, razón por la que los mercados evaluados se consideran agroecológicos y no orgánicos. Mientras para el MADR, un sistema de producción orgánico agropecuario, acuícola o pesquero, conserva la biodiversidad y los ciclos biológicos de los ecosistemas, excluyendo insumos sintéticos y reduciendo los insumos externos (Ministerio de Agricultura y Desarrollo Rural - MADR, 2006), la agroecología plantea que este manejo ecológico de los bienes comunes ocurra mediante la acción colectiva, no solo en la fase productiva, sino también en las de circulación alternativa y consumo (Sevilla-Guzmán, 2006). Por tanto, la propuesta de sostenibilidad de la producción orgánica se queda corta al excluir las dimensiones social, económica y política de la producción, la distribución y el consumo, pero además se ha desvirtuado en diversos aspectos, convirtiéndose en un sistema injusto (Kröger y Schäfer, 2014).

Adicionalmente, una diferencia legal entre producción orgánica y agroecológica, en Colombia, es que en el primer caso es obligatoria la certificación de tercera parte (Ministerio de Agricultura y Desarrollo Rural - MADR, 2006), mientras que en el segundo caso las certificaciones suelen ser participativas, según fue aprobado recientemente (Ministerio de Agricultura y Desarrollo Rural - MADR, 2017).

\section{Metodología}

Esta es una investigación descriptiva de tipo mixto - cuantitativa y cualitativa-, para la cual se recolectó información en el primer semestre de 2018, mediante la aplicación de una encuesta a consumidores de productos agroecológicos de la RMABR.

La población total abarcó a 816 consumidores de la RMABR, y la muestra se calculó con un nivel de confiabilidad del $80 \%$, un nivel máximo de error del $5 \%$ y una heterogeneidad del $50 \%$, para un total de 149 consumidores encuestados. El muestreo fue de tipo no probabilístico, accidental.

La encuesta aplicada incluyó veintiséis preguntas, fue diseñada por las autoras a partir del estudio de Ipsos (2008), ajustándola a las necesidades de la red e incluyendo temas de interés para todos los mercados de la RMABR. El instrumento finalmente se socializó y validó con los promotores de la RMABR, posteriormente se aplicó un piloto a dos personas para verificar la claridad del lenguaje y el cumplimiento del objetivo de la investigación a partir de las respuestas generadas, y finalmente se divulgó por correos electrónicos y redes sociales de cada mercado de la RMABR, para su diligenciamiento. 
La encuesta incluyó un primer aparte para la caracterización sociodemográfica de los consumidores, con siete preguntas -edad, género, nacionalidad, ocupación, nivel educativo, nivel de ingresos y número de personas que conforman el hogar-; en el segundo aparte se incluyeron 15 preguntas para caracterizar el consumo -mercados, productos, frecuencia, gasto, motivaciones de compra y no compra, sobreprecio dispuesto a pagar, medios de comunicación, entre otras-; y un tercer aparte que incluyó cuatro preguntas, que evaluaron las tendencias en participación y compras, y las recomendaciones de los consumidores a los mercados. Las preguntas fueron cerradas, de opción múltiple, aunque en varias de ellas se incluyó la opción "Otro" que era de respuesta abierta.

Los encuestados están ubicados en Bogotá. Los resultados Recuperados fueron analizados mediante estadística descriptiva y comparación con otros estudios similares Recuperados mediante revisión de literatura.

\section{Resultados y discusión}

Del total de las encuestas realizadas (149), 46 personas compran en mercados a domicilio, 63 personas compran en mercado tipo feria, y 40 personas compran en mercado a domicilio y en mercado tipo feria a la vez. A continuación, se presentan los resultados:

\section{Edades}

Para la pregunta inicial, que corresponde a la edad de los encuestados, se clasificó en cinco grupos (Martín, 2005), como se muestra en la figura 1, el resultado indica un porcentaje mayoritario del $60 \%$ de adultos jóvenes. El promedio de edad es de 37 años, la moda de 35, y el rango de 19 a 70 años. 


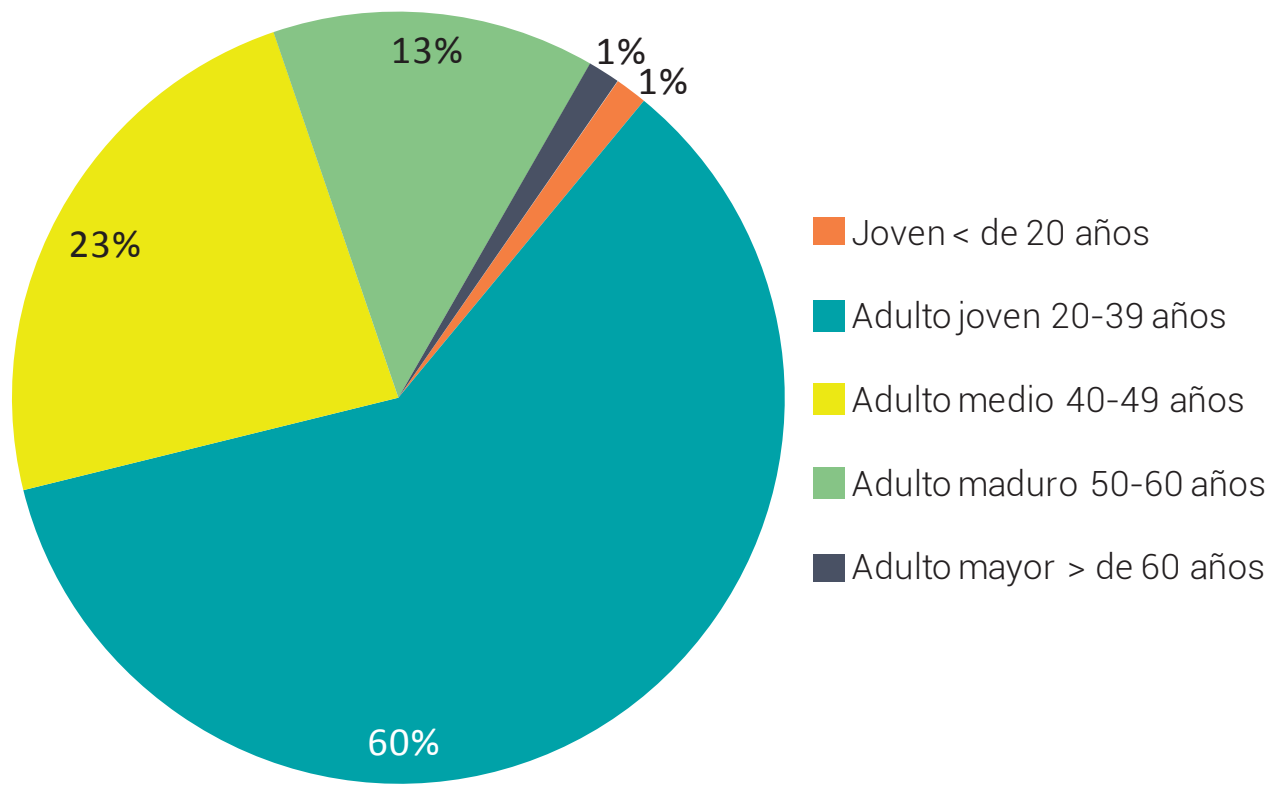

Figura 1. Edades de consumidores.

Fuente: elaboración propia

Estos resultados son similares a los del estudio de Arroyave (2015), quien reporta que la mayoría de los consumidores ecológicos en Antioquia están entre 20 y 60 años; el estudio de Vargas y Valencia (2015), que reporta que un 55,3\% de las consumidoras verdes de Bogotá tienen entre 20 y 40 años. En promedio, en un estudio realizado por estudiantes de la Universidad Javeriana en varios mercados del país, la mayoría de los compradores de productos agroecológicos son mayores de 30 años (Prada, 2017); igual pasa con el estudio de Escobar-Moreno, Gil y Restrepo (2015), quienes reportan un promedio de 34 años para el consumidor verde antioqueño. Ocurre algo similar en otros países, en Serbia reportan que el 80,0 \% de consumidores tienen entre 21 y 50 años (33,8 \% están entre 31 y 40 años) (Kranjac, Vapa-Tankosić, y Knežević, 2017).

Estos resultados, a nivel país, pueden deberse a que los adultos jóvenes y medios (20 a 49 años), principalmente, han crecido en la época de desarrollo de la producción orgánica en Colombia que, según Sánchez (2017), comienza su historia desde 1980, y más recientemente, en la época de desarrollo de la agroecología, que se registra desde los años setenta y ochenta (León-Sicard, y otros, 2015). A nivel mundial, desde los años sesenta y setenta, se empezaron a evidenciar las consecuencias de la revolución verde en forma de acumulación de desechos, contaminación del aire, agua y suelo, pérdida de la biodiversidad, y agotamiento de los recursos naturales, entre 
otras (Ceccon, 2008), por lo que, las personas que al momento de este estudio tenían menos de 58 años, han estado expuestas a algún proceso de educación ambiental a raíz de estos sucesos.

\section{Géneros}

En la segunda pregunta se consultó por el género de los participantes, los resultados se presentan en la figura 2:

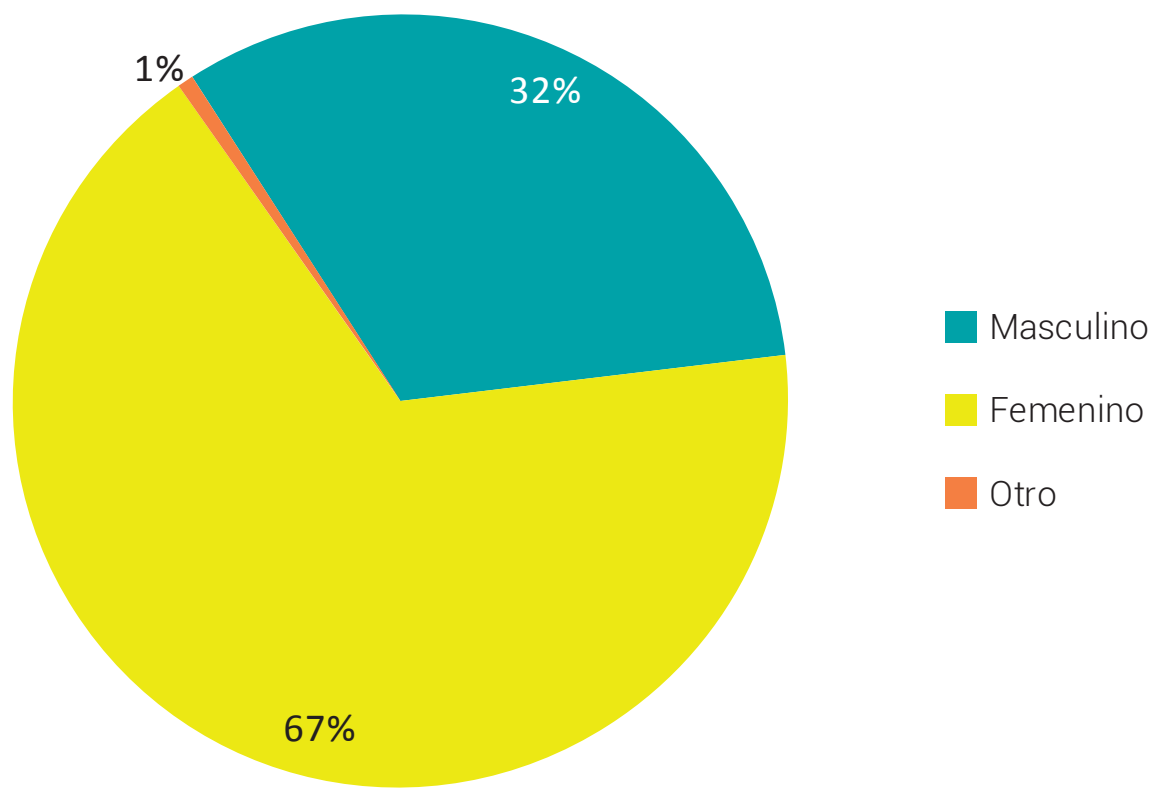

Figura 2. Género de consumidores.

Fuente: elaboración propia

Estos resultados son más bajos que el 80 \% reportado en consumidores verdes antioqueños (Escobar-Moreno, Gil y Restrepo, 2015), pero muy similares a los reportados en Noruega, donde el 68 \% de consumidores orgánicos son mujeres (Storstad y Bjørkhaug, 2003), aunque más altos que el 42,7 \% de Serbia (Kranjac, Vapa-Tankosić, y Knežević, 2017). Según Herrera (2006), en Colombia son las mujeres quienes dedican más tiempo para hacer las compras del hogar, pero además, desde el ecofeminismo se confirman más acciones de protección ambiental en mujeres que en hombres (Hosseinnezhad, 2017). 


\section{Nacionalidad}

Respecto a la tercera pregunta, hay más de cuatro nacionalidades presentes entre los encuestados, como se presenta en la figura 3.

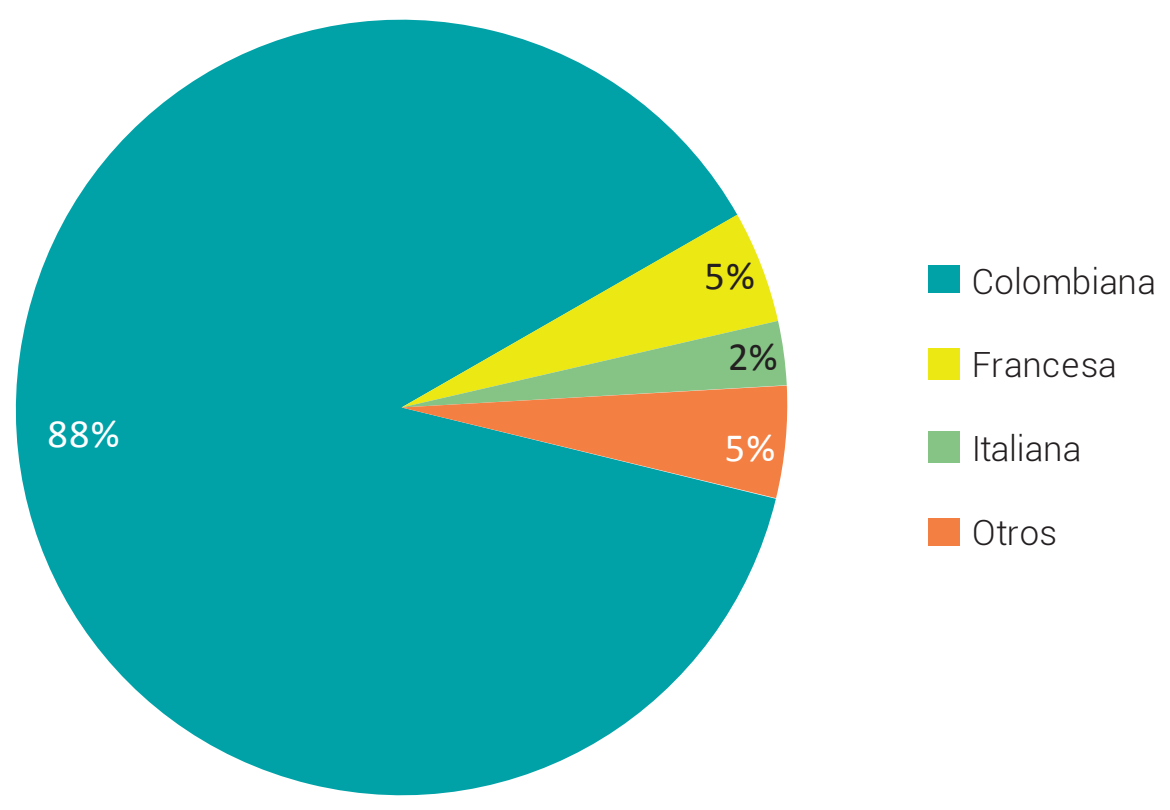

Figura 3. Nacionalidad de consumidores Fuente: elaboración propia

Resalta que un $12 \%$ de los encuestados consumidores no son colombianos. Según Willer y Lernoud (2017) el segundo país con el mercado orgánico más grande de Europa es Francia (5,5 mil millones de euros), y el cuarto es Italia (2,3 mil millones de euros). Aunque Francia e Italia están representados en un porcentaje bajo del total de los encuestados, podemos ver que estas personas buscan mercados que ofrezcan productos de origen agroecológico en su país de residencia. Este resultado se ve influenciado por la participación en la investigación del mercado agroecológico Sembrando Confianza, de la Fundación Proyectar Sin Fronteras, ONG colombo francesa.

\section{Ocupación}

Para describir cual es la ocupación de las personas encuestadas se agrupo según la versión 2017 de clasificación nacional de ocupaciones (SENA, 2017) en 10 grupos, de los cuales $24 \%$ están vinculadas con "ciencias sociales, educación, servicios 
gubernamentales y religión" -administración de justicia, enseñanza, investigación en ciencias sociales y desarrollo y administración de políticas y programas gubernamentales-; seguido del 19 \% cuya labor tiene que ver con "ciencias naturales, aplicadas y relacionadas" -investigación, desarrollo y aplicación de las matemáticas y las ciencias naturales en ingeniería, arquitectura, urbanismo y afines-; y en tercer lugar $14 \%$ se ocupan en "arte, cultura, esparcimiento y deportes" - ofrecer entretenimiento, esparcimiento y comunicación, y están relacionadas con arte, cultura, artes escénicas, periodismo, literatura, diseño creativo y deporte-; en un menor porcentaje $9 \%$ de personas vinculas con ventas y servicios; 6 \% explotación primaria y extractiva, 4 \% finanzas y administración, 4 \% en dirección y gerencia; y 3 \% se desempeña en salud. El $7 \%$ de los encuestados no se encuentran en ninguna de estas opciones, ya que únicamente se dedican a estudiar y el $10 \%$ restante están en ocupaciones diferentes.

Aunque los encuestados se encuentran en más de ocho ramas ocupacionales diferentes catalogadas como profesionales, se puede decir que sin importar su profesión hay un impacto positivo y una fuerte conexión en cuanto a la concientización del beneficio de producir y consumir alimentos orgánicos (Muhammad, Fathelrahman, y Ullah, 2016). Si bien resalta que la ocupación más frecuente sean las ciencias sociales y no las naturales, y que un porcentaje tan bajo este en el sector salud. Hay que aclarar que, en muchos casos, posiblemente en la mayoría, las personas no diferencian entre producto orgánico y agroecológico.

\section{Nivel de estudios}

En la quinta pregunta, se consultó por el nivel de estudios del encuestado, los resultados se presentan en la figura 4: 


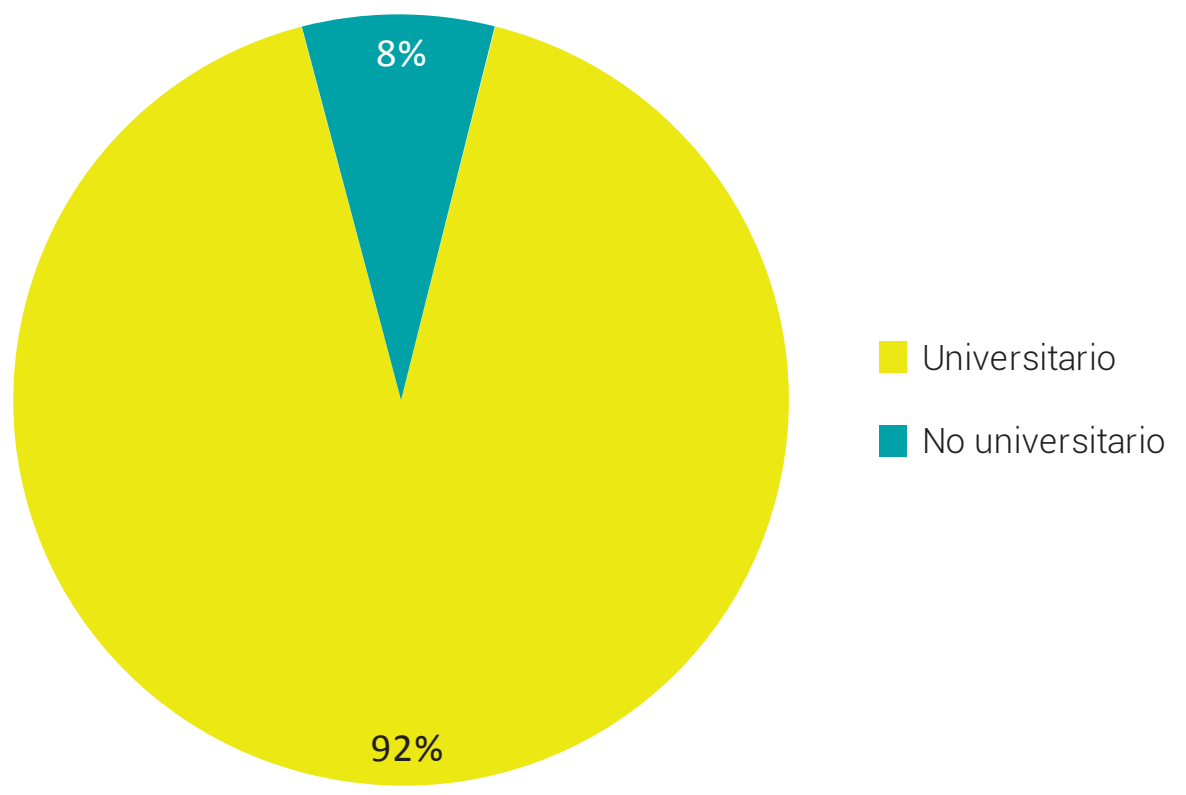

Figura 4. Nivel educativo de consumidores Fuente: elaboración propia

Según estudios realizados en Noruega (Storstad y Bjørkhaug, 2003), Colombia [(Vargas y Valencia, 2015), (Arroyave, 2015) y (Prada, 2017)], Emiratos Árabes Unidos (Muhammad, Fathelrahman, y Ullah, 2016), y Serbia (Kranjac, Vapa-Tankosić, y Knežević, 2017), la mayoría de los consumidores de productos orgánicos cuentan con un nivel educativo universitario o superior -incluso posgrados-.

Se presume que estos consumidores hayan recibido educación ambiental, lo que, según Maldonado, Rivas, Molina, y Flores (2007) es la principal variable explicativa de la conducta del consumidor verde, especialmente en aspectos como orientación humano-naturaleza, conocimiento ecológico, control percibido, consecuencias personales y consecuencias ambientales.

Hasta aquí, variables como edad, género y nivel educativo, tienen un efecto sobre las actitudes hacia el ambiente, de manera que los jóvenes, las mujeres y las personas con educación superior tienden a estar más preocupados por este tema (Storstad y Bjørkhaug, 2003).

\section{Ingresos}

En cuanto a los ingresos, el $40 \%$ de los encuestados, tiene ingresos de menos de uno y hasta dos salarios mínimos mensuales legales vigentes (SMMLV), que según los Decretos 2269 y 2270 del 2017 del Ministerio de Trabajo, corresponden a \$869 453 
para 2018, incluyendo el auxilio de transporte, en personas que reciban hasta dos SMMLV; mientras que el $37 \%$, tienen ingresos de más de cuatro SMMLV, que corresponden a más de \$3 124 968, como se presenta en la figura 5.

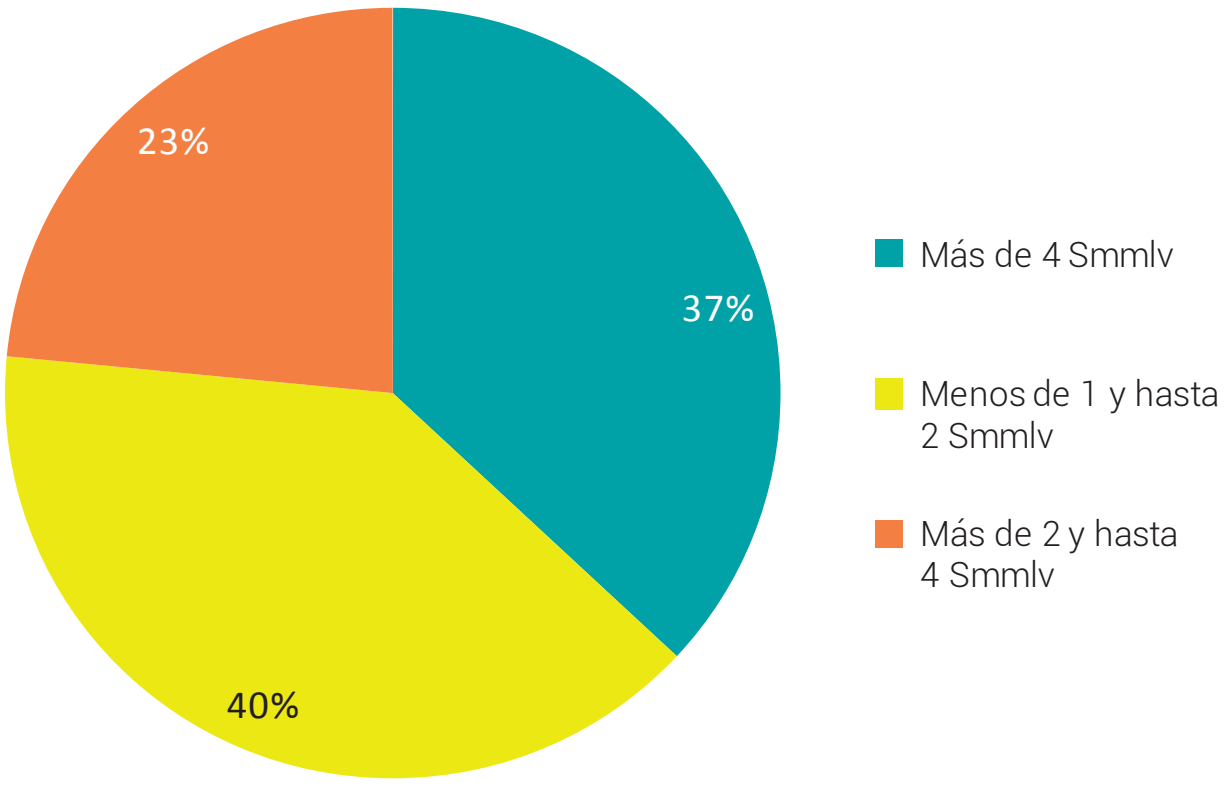

Figura 5. Ingresos de consumidores.

Fuente: elaboración propia

Estos resultados difieren de los de Escobar-Moreno, Gil y Restrepo (2015), en cuyo estudio el nivel de ingresos mayoritario en Antioquia es de 2 a 4 SMMLV, y el de Vargas y Valencia (2015) en Bogotá con 2 a 5 SMMLV. Estos estudios coinciden parcialmente con el de Serbia, en donde la mayoría de consumidores orgánicos tienen ingresos más altos (Kranjac, Vapa-Tankosić, y Knežević, 2017).

En este caso, los resultados no son tan claros como en la caracterización de edad, género, y nivel de estudios, por lo que puede deberse a que, según Storstad y Bjørkhaug (2003), no hay correlacion entre el consumo de orgánicos y el ingreso, o a que no es una variable netamente explicativa (Kranjac, Vapa-Tankosić, y Knežević, 2017).

Parte de la explicación de este hallazgo es que, por lo menos dos de los mercados de la RMABR (FAU y Agrosolidaria Engativá), vinculan especialmente a consumidores de estratos socioeconómicos 3 y 2, que corresponden a estratos medio-bajo y bajo, respectivamente. 


\section{Hogares}

Al consultar en la pregunta siete por cuantas personas conforman el hogar, se puede ver en la figura 6 que $34 \%$ de los encuestados, corresponde a hogares conformados por dos personas; seguido de un $55 \%$ de encuestados con hogares conformados por tres personas o más, mientras los hogares de una sola persona corresponden al $11 \%$.

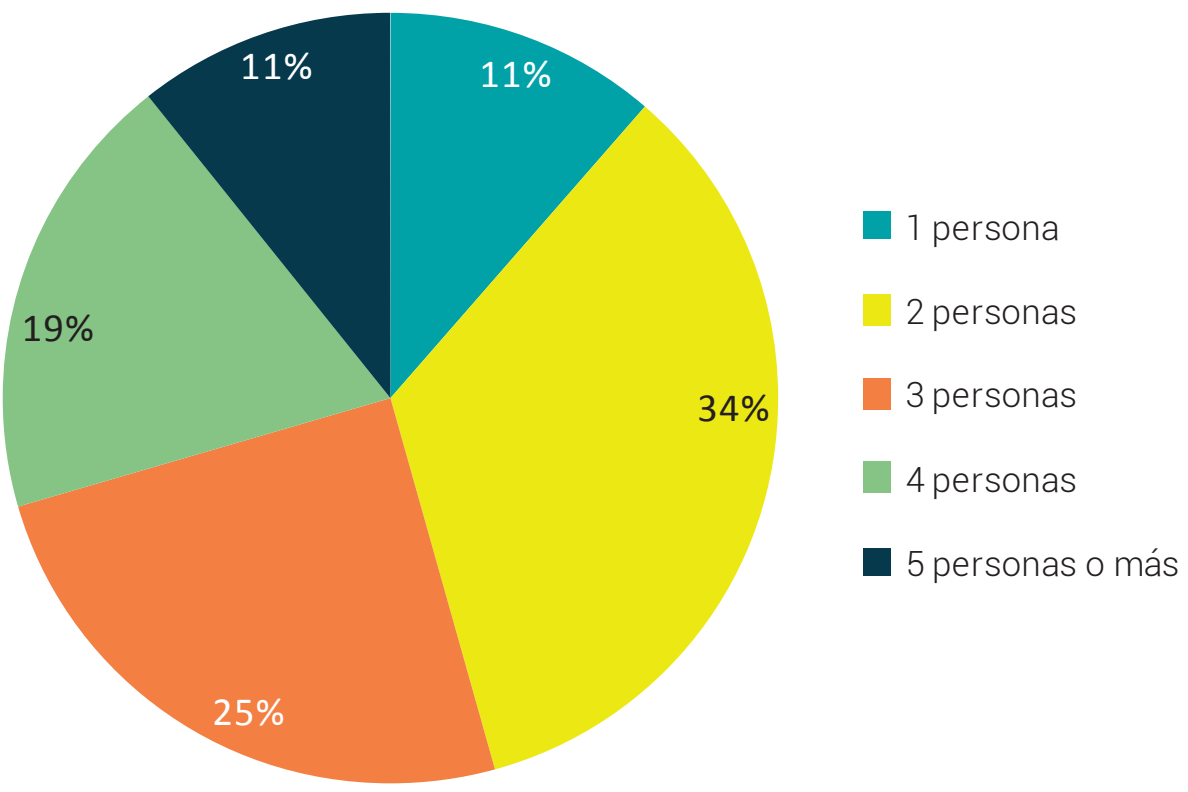

Figura 6. Número de personas que conforman el hogar.

Fuente: elaboración propia

Los resultados son muy similares a los reportados en Argentina por Gentile y Rodríguez (2002) donde la mitad de los hogares de los consumidores estan conformados por más de tres personas, el 35 \% son hogares conformados por dos personas y el $15 \%$ son hogares unipersonales. Según el censo del DANE realizado en 2005, el $73,5 \%$ de hogares estan conformados por tres personas o más (DANE, 2010), indicando que los hogares del estudio son más pequeños, lo que se podría interpretar como una mayor destinación de gasto a cada miembro del hogar.

Los resultados difieren del estudio de Serbia, donde los hogares son mas grandes, por lo que el 89,4\% de los consumidores tienen hogares de hasta cuatro miembros (Kranjac, Vapa-Tankosić, y Knežević, 2017). Contrariamente, según Vargas y Valencia (2015), en Bogotá hay más potencial de compra en mujeres solteras o separadas sin hijos mientras que en Ecuador, la tenencia de hijos no es determinante (Andrade y Flores, 2008). Según estos hallazgos, el tamaño del hogar no es muy determinante en la compra. 


\section{Número de mercados de la RMABR donde se realizan compras}

En la figura 7 se presenta el número y tipo de mercados de la RMABR en que los encuestados consumidores realizan sus compras.
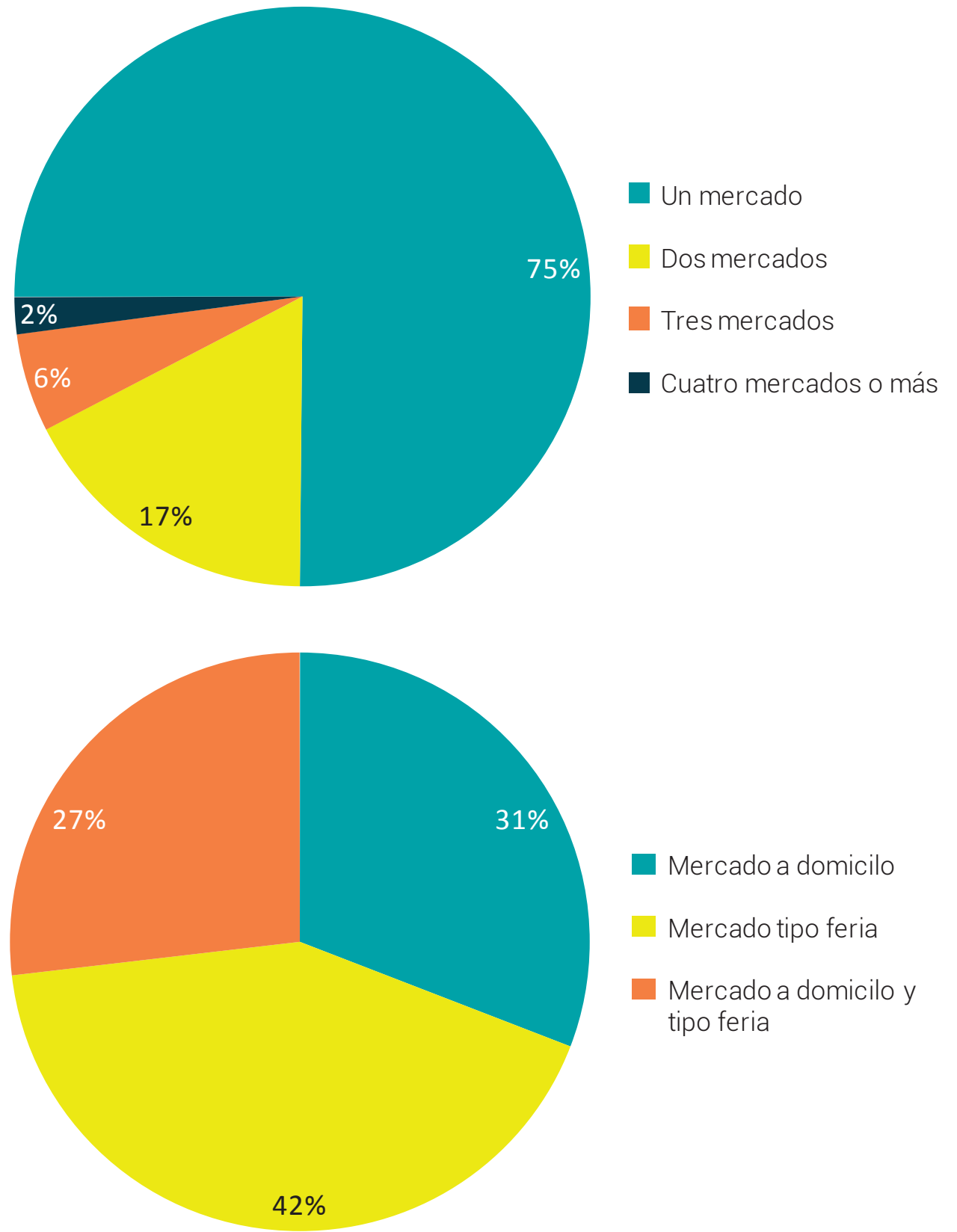

Mercado a domicilo

Mercado tipo feria

Mercado a domicilo y tipo feria

Figura 7. Número y tipo de mercados de la RMABR en los que realizan las compras.

Fuente: elaboración propia 
El $75 \%$ de los encuestados compra en un solo mercado de los ocho que hacen parte de la RMABR. Algunas razones expuestas por los encuestados del por qué hacen sus compras en estos mercados, es que el mercado en el que compran es cercano a su lugar de residencia, que no conocen los otros mercados, o que están muy distanciados para hacer las compras en varios mercados. Precisamente, el desconocimiento de los mercados fue una respuesta común en el 23 \% de las encuestadas en el estudio de Vargas y Valencia (2015).

De los encuestados, el 31 \% compra en mercados a domicilio, el $42 \%$ en mercados tipo feria y el $27 \%$ hacen sus compras en los dos tipos de mercado. Las respuestas más populares fueron: 26 de 149 encuestados consumidores compran solo en la Feria Agroecológica UNIMINUTO, 22 de 149 compran solo en Mercado Agroecológico Campesino, 15 de 149 compran únicamente en Mercado Agroecológico Tierra Viva, 12 de 149 compra únicamente en Sembrando Confianza, 11 de 149 compra únicamente en Domicilios Semilla Andina, 10 de 149 compra únicamente en Agrosolidaria Engativá, 8 de 149 compra únicamente en La Canasta, 7 de 149 compran en ALaCena y Feria Agroecológica UNIMINUTO, mientras las demás combinaciones de respuestas tuvieron menos de siete respuestas.

En el Valle de Aburrá, en Colombia, se identificó que la mayoría de los consumidores prefieren comprar en tiendas donde estén disponibles los productos orgánicos, siendo menos importante el mercado a domicilio y la cercanía de las tiendas (Escobar-Moreno, Gil, y Restrepo, 2015). Mientras el estudio de Vargas y Valencia (2015) en Bogotá, indica que el 77 \% prefieren comprar estos productos en supermercados y el $55 \%$ en tiendas naturistas, similar a lo reportado en Serbia (Kranjac, Vapa-Tankosić, y Knežević, 2017), donde el 72 \% prefiere comprar en supermercados y tiendas de alimentos saludables, mientras solo el $20 \%$ directamente con productores y el $8 \%$ en tiendas especializadas. Las diferencias entre estudios colombianos estuvo influenciada por el lugar de realización de las encuestas.

Según Vietoris, y otros (2016) en una encuesta realizada a 350 consumidores, los encuestados prefieren comprar directamente a productores. Comparativamente, en el estudio de Andalucía, los principales canales de compra fueron hipermercado, tienda y cooperativa de consumidores, siendo los dos primeros los más importantes y el tercero siendo más importante en el caso del aceite (Ipsos Insight, 2008). Hay que resaltar, que, en Andalucía, las ventas de productos ecológicos podrían ser mayores, si, según los encuestados, mejorara su distribución y se ofertaran con más frecuencia y diversidad, en canales tradicionales. En Serbia, el 28 \% de respuestas incluyen la preferencia de compra en mercados, seguida por grandes mercados (23\%), tiendas 
de alimentos saludables (21\%), directamente de productores (20\%) y tiendas especializadas (7 \%) (Kröger y Schäfer, 2014).

Parte de la diferencia entre comprar a un productor -feria- o a un intermediario - supermercado, tienda-, según Kröger y Schäfer (2014), es que algunos productos y servicios orgánicos ya no son distinguibles en términos de precio y calidad, por lo que la ética entra hacer parte importante del proceso de escogencia del tipo de mercado, ya que permite conectar a agricultores y consumidores, surgiendo en el consumidor cada vez más una preocupación por los "otros". Este enfoque ético es muy sentido en los mercados agroecológicos evaluados, en donde los consumidores conocen a los productores, sea porque asisten a un mercado tipo feria, o porque se hacen reuniones entre estos y los productores, con cierta periodicidad.

\section{Definición de "producto agroecológico" por parte de los encuestados}

Cuando se preguntó a los encuestados sobre cuál es su definición de productos agroecológicos en la pregunta 10, estos tenían tres opciones o su propia definición: son producidos sin fertilizantes y pesticidas sintéticos, ni organismos genéticamente modificados; son productos Recuperados de la agricultura sostenible; son productos locales, no industrializados y naturales. El 73 \% respondieron que los productos agroecológicos "son producidos sin fertilizantes y pesticidas sintéticos, ni organismos genéticamente modificados"; 11 \% combinaron esta respuesta con la opción de "productos Recuperados de la agricultura sostenible", 11 \% combinaron la respuesta con "productos locales, no industrializados y naturales", 21 \% combinaron las tres opciones y una persona añadió a esta combinación la definición de "cultivados con amor". El $14 \%$ escogieron como única respuesta "Productos Recuperados de la agricultura sostenible"; el 11 \% escogió como única respuesta "Productos locales, no industrializados y naturales".

El restante $2 \%$, decidió dar su propia definición sobre productos agroecológicos: "Son productos locales producidos con un uso razonable de los recursos renovables (agua, suelo) y pocos productos sintéticos o ninguno si es posible", "Producto producido sin fertilizantes ni pesticidas, sin procesamiento industrial o químico, naturales basados en un sistema de producción integral sostenible y con sentido social", y "Productos con estricta trazabilidad y manejo agroecológico".

En un estudio realizado en Argentina los consumidores definen un producto orgánico como un producto libre de pesticidas y natural (Gentile y Rodríguez, 2002), lo que parcialmente y en versión abreviada corresponde a las definiciones ofrecidas 
en este estudio a los consumidores encuestados, sobre todo a la primera y tercera opciones de respuesta. Sin embargo, hay que aclarar que, según Higuchi (2015), más de la mitad de todos los consumidores orgánicos del mundo creen que los productos naturales no contienen pesticidas.

Las respuestas de los consumidores pueden deberse a que todos los integrantes de la RMABR brindan información y educación constante, e incluso la RMABR dispone de una página web con la definición de agroecología que ha adoptado colectivamente $^{2}$. Los resultados de esta investigación coinciden, aunque no textualmente, con la definición de la RMABR para la producción orgánica/agroecológica, que se refiere a la producción de alimentos frescos, procesados, productos para el aseo personal, medicinales y cosméticos, que vincula las dimensiones ambiental, social y económica de la producción; tiene en cuenta a las personas, su cultura, sus saberes ancestrales y los nuevos conocimientos; está centrada en procesos más que en insumos; no emplea insumos agroquímicos e insumos externos que sean nocivos para la salud humana o ambiental; promueve la sostenibilidad del sistema gracias a la conservación y el uso sostenible de los bienes comunes y busca el bienestar de productores y consumidores (Chaparro y Naranjo, 2018).

\section{Caracterización del consumo}

Para la pregunta once, se le presentó a los encuestados un listado de productos que se ofrecen en la RMABR, para que escogieran cuáles compran o han comprado. Entre estas opciones, lo que más compran, con un 39 \%, es arroz, quinua, cebada, maíz y otros cereales en grano o harina, siendo esta su primera opción de compra, y luego mencionan añadir a su mercado dos, tres o más productos del listado como frutas y verduras, conservas de frutas y verduras, huevos, leche y derivados lácteos, legumbres, miel, pólen y otros productos apícolas -abejas-, productos de panadería y pastelería, productos preparados listos para el consumo -empanadas, envueltos, hamburguesas, entre otros-, otros alimentos procesados - café, panela, té, chocolate y demás-, cosméticos, artesanías, medicinales, plantas, y productos de aseo personal.

En segundo lugar, aunque con una mínima diferencia, el 37 \% de las personas compran principalmente frutas y verduras, y luego añaden a su mercado la combinación de dos o más productos adicionales como huevos, miel y conservas de frutas y verduras. En tercer lugar, el 9 \% compran como prioridad aceites, productos de panadería y pastelería, y adicionan al mercado arroz, quinua, cebada, maíz y otros cereales

2 Para más información puede consultarse la página: https://redmercadosagroecologicosbogota.co/ 
en grano o harina. El $2 \%$ compran carne, pollo y pescado, frutas y verduras, huevos, legumbres, otros alimentos procesados - café, panela, té, chocolate, entre otros-; otro $2 \%$ compra solo conservas de frutas y verduras, productos de panadería y pastelería, otros alimentos procesados - café, panela, té, chocolate y otros-; y el restante $11 \%$ son las compras puntuales que hace una o dos personas como artesanías, cosméticos, productos preparados listos para el consumo -empanadas, envueltos, hamburguesas, entre otros-.

Estos resultados coinciden con el estudio realizado en Andalucía (Ipsos Insight, 2008) y un estudio realizado en Ecuador (Ortiz y Florez, 2008), en donde lo que más compran los consumidores orgánicos son verduras y frutas, mientras lo segundo más comprado en Ecuador son cereales. Estos resultados también coinciden con los de Serbia (Kranjac, Vapa-Tankosić, y Knežević, 2017) aunque allí el orden de preferencia es: vegetales, frutas, cereales y productos lácteos. De manera similar y según Martínez (2016), en el mercado orgánico de Cajicá los productos que más consumen son principalmente hortalizas, frutas frescas, granos, huevos, miel, infusiones, cereales y frutos secos.

En este estudio sorprendió que el producto más comprado no fueran los vegetales y las frutas, como si ocurre en la mayoría de los demás estudios, aunque fue la segunda categoría más comprada luego de cereales y con una diferencia mínima. Se podría decir que estos resultados sobre preferencias de consumo varían de acuerdo con la oferta que brinda cada mercado, y a las necesidades o hábitos de consumo de quienes compran, si bien se debe resaltar que la oferta de hortalizas es superior a la de cereales en todos los mercados evaluados, por lo que es de gran interés la demanda por cereales.

\section{Motivaciones de compra de productos agroecológicos}

La pregunta doce indagó las motivaciones para comprar productos agroecológicos, eligiendo entre cinco opciones, la combinación de varias de ellas o dar su propia respuesta.

Del total de los encuestados, el 73 \% compra productos agroecológicos por salud, aunque también combinan esta motivación con que contribuyen a mantener en buenas condiciones el medio ambiente, son de mejor calidad -olor, sabor, frescura, otros-, contribuyen a un sistema social más justo y son productos de origen local. De otro lado, la motivación del 13 \% combina dos opciones: contribuyen a mantener en buenas condiciones el medio ambiente y contribuyen a un sistema social más 
justo. La motivación de compra para el 9 \%, es porque los productos agroecológicos contribuyen a un sistema social más justo.

Estos resultados coinciden con otros. En Bogotá la principal motivación de compra fue la salud -23\% por recomendación médica- en el estudio de Vargas y Valencia (2015), igual que en España (Insight, 2008), Argentina (Gentile y Rodríguez, 2002), Serbia (Kranjac, Vapa-Tankosić, y Knežević, 2017) y la India Kochin (Krishna y Balasubramanian, 2018), lo que puede deberse a que se han descubierto y son más reconocidos, algunos de los impactos negativos de la producción convencional de alimentos en la salud de las personas, y por eso, estas han optado por consumir alimentos orgánicos y ecológicos, pues como presenta Raigón (2008), son alimentos inocuos al no ser producidos con insecticidas, herbicidas, fertitlizantes de síntesis y aditivos -estos últimos en el caso de los procesados-. Además, tienen más nutrientes y estos son de mejor calidad, como en el caso de las vitaminas, minerales, antioxidantes, proteínas y grasas. En este aspecto hay que recordar, que la mayoría de consumidores no diferencian entre producto agroecológico y orgánico, sobre todo respecto al hecho de que durante su producción no se emplean insumos de síntesis química, si bien la diferencia entre estos dos conceptos queda en evidencia cuando los consumidores eligieron respuestas diferentes a la motivación por salud.

\section{Motivaciones de no compra de productos agroecológicos}

En la pregunta 13 se indagó sobre cuáles serían los motivos por los que los encuestados no compran productos agroecológicos en mayor volumen o con más frecuencia.

El 59 \% respondió que el precio es el principal motivo: "por ser más costosos los productos, no se puede invertir más dinero en un mercado", o "porque hay otras necesidades que cubrir". De esas 88 personas, 31 personas combinaron la respuesta con "no encuentro ciertos productos agroecológicos en la RMABR", "no hay puntos de venta o entregas permanentes", o "se dañan muy rápido" - como ejemplo dieron: panes, arepas, quesos, y otros-. El $19 \%$ no encuentra ciertos productos agroecológicos en la RMABR y el $14 \%$ argumenta que no hay puntos de venta o entregas permanentes. El restante $8 \%$, manifiesta viajar con frecuencia, consumen poco, no tienen claras las ventajas de consumir ciertos productos agroecológicos, no tienen quien reciba la compra entre semana, tienen poco espacio para almacenamiento, el peso del mercado les impide comprar más, y porque tienen poco tiempo.

La investigación en Andalucía también registró el precio como principal freno para la compra, por lo que suponen que es una barrera para que lleguen nuevos 
consumidores o para que los actuales se mantengan fieles (Ipsos Insight, 2008). Según Aschemann-Witzel y Zielke (2015). El precio es la mayor barrera percibida para la compra, y explican que esto depende del rol que el consumidor cumpla en el momento de comprar, un rol positivo significa que el precio más alto es señal de calidad y un rol negativo indica que se debe hacer un sacrificio para poder adquirir el producto. El rol se define según sus ingresos, si son bajos el consumidor adquiere el rol negativo y si son altos adquiere el rol positivo, la barrera del precio se identifica más en las personas que siempre están buscando precios bajos o que no son consumidores permanentes de productos agroecologicos y para los consumidores con ingresos altos el precio más alto de los productos agroecologicos son señal de calidad y precio justo para los productores.

Para Henryks, Cookse, y Wright (2014), las mayores barreras para la no compra de productos agroecológicos son el precio y la poca disponibilidad de los productos en una sola tienda, obligando al consumidor a ir a varios lugares especializados, lo que desanima al consumidor.

Hay que añadir que el precio no ha sido una barrera para muchos de los consumidores de este estudio como lo demuestran sus ingresos mayoritarios, y esto puede deberse a que un precio alto de un producto del que se han informado claramente sus beneficios o del que el consumidor ha comprobado sus beneficios, deja de ser alto en la percepción del consumidor y se convierte en justo.

\section{Productos que quisieran encontrar en la RMABR}

A los encuestados les gustaría poder encontrar en los mercados de la RMABR productos de aseo para el hogar como estropajos que reemplacen las esponjas, detergentes, productos de aseo personal como cepillos, crema dental, talcos, desodorante, jabones, cosméticos, productos de hogar como platos ecológicos. En cuanto a productos alimenticios, les gustaría encontrar pastas, leche, centeno, avena, lentejas, maíz peto, frutas como mortiño, uva camarona, limón mandarino, arándanos, moras, manzanas, peras, uvas y duraznos nacionales, guanábana, frutas exóticas, frutos secos, hortalizas como batata, maní, berenjena, alcachofa, cubios, rugula, guatila, pimentón, más variedad de setas, plantas aromáticas y medicinales. También buscan carne de res, pollo, pescado, embutidos cárnicos, salchichas y chorizos veganos, alimentos para mascotas, ropa para toda la familia, y varios encuestados quisieran encontrar semillas, plántulas, fertilizantes y abonos orgánicos, así como libros sobre agroecología.

Algunas personas también quisieran que los productos básicos siempre estén disponibles como: cebolla larga, cabezona, puerro y ajo, productos preparados como 
yogurt griego en presentación grande, milanesas de quinua, productos sin gluten como pan y diferentes harinas, productos sustitutos de proteína, bebidas refrescantes, licor, golosinas o dulces, cereales secos, diferentes snacks, quesos maduros y quesos de leche de cabra, toda clase de pastelería y repostería, comidas rápidas, miel de caña, arepas y galletas.

En el estudio de Andalucía, la gran mayoría de los encuestados manifestaron intención de compra de productos diferentes a los que actualmente consumen, siendo las principales categorías en respectivo orden: verduras - principalmente lechuga, tomate y cebolla - y frutas - principalmente naranja, pera, manzana- (Ipsos Insight, 2008), lo cual coincide parcialmente con los hallazgos de esta investigación.

Las preferencias de los consumidores sobre productos o alimentos que les gustaría encontrar en la RMABR, le permite a los productores identificar fallas en el sistema de producción y corregir situaciones como producir más variedad y planear mejor la producción para poder ofertar este tipo de productos que no se encuentran o que no se ofertan con mayor frecuencia, por cuestiones como los tiempos de cultivo, variedad de climas y otras variables que entran hacer parte de un proceso de siembra y cosecha, pero para las cuales se pueden plantear estrategias que permitan llegar al consumidor con mucha más variedad y seguridad de oferta, en los productos primarios de origen agrícola.

Respecto a los demás productos, podemos categorizarlos, aparte de frutas y verduras, en productos que están en algunos mercados - productos de aseo personal y para el hogar, ropa, cárnicos, alimentos para mascotas, insumos para huertas, libros, licores, pastelería y repostería, más harinas, cereales y snacks, entre otros-, pero no en todos, ya sea por dificultades logísticas - oferta en algunos momentos, oferta permanente, almacenamiento, capital de trabajo, entre otras-, lo que hace que muchos consumidores no los conozcan.

Otra categoría son los productos que no se ofertan en la actualidad, dada la escasa oferta de los productores que prefieren destinarlos a autoabastecimiento lentejas-, por las dificultades de no contar con red de frío -leche, carnes-, porque el bajo volumen de ventas no permite ofertarlos - carne de res-. En el caso de pastas un único emprendimiento las ofertó en la FAU, pero fue necesario sacarlo del mercado por problemas con el desarrollo del producto. En el caso de los platos, se están desarrollando en la actualidad con el apoyo de investigadores de UNIMINUTO.

La última categoría son los productos que definitivamente no se producen con calidad agroecológica como la avena (Ministerio de Agricultura y Desarrollo Rural, 2018), o de los que incluso no hay producción nacional, este es el caso del centeno (FENALCE, 2018). 


\section{Gasto en mercados agroecológicos}

Para saber cuánto invierten los encuestados en un mercado agroecológico, se dieron cuatro opciones de respuesta, los resultados se presentan en la figura 8. Estos resultados son parcialmente consistentes con los resultados de la pregunta seis donde uno de los porcentajes más altos de respuestas es para los que ganan menos de uno o dos SMMLV (40\%).

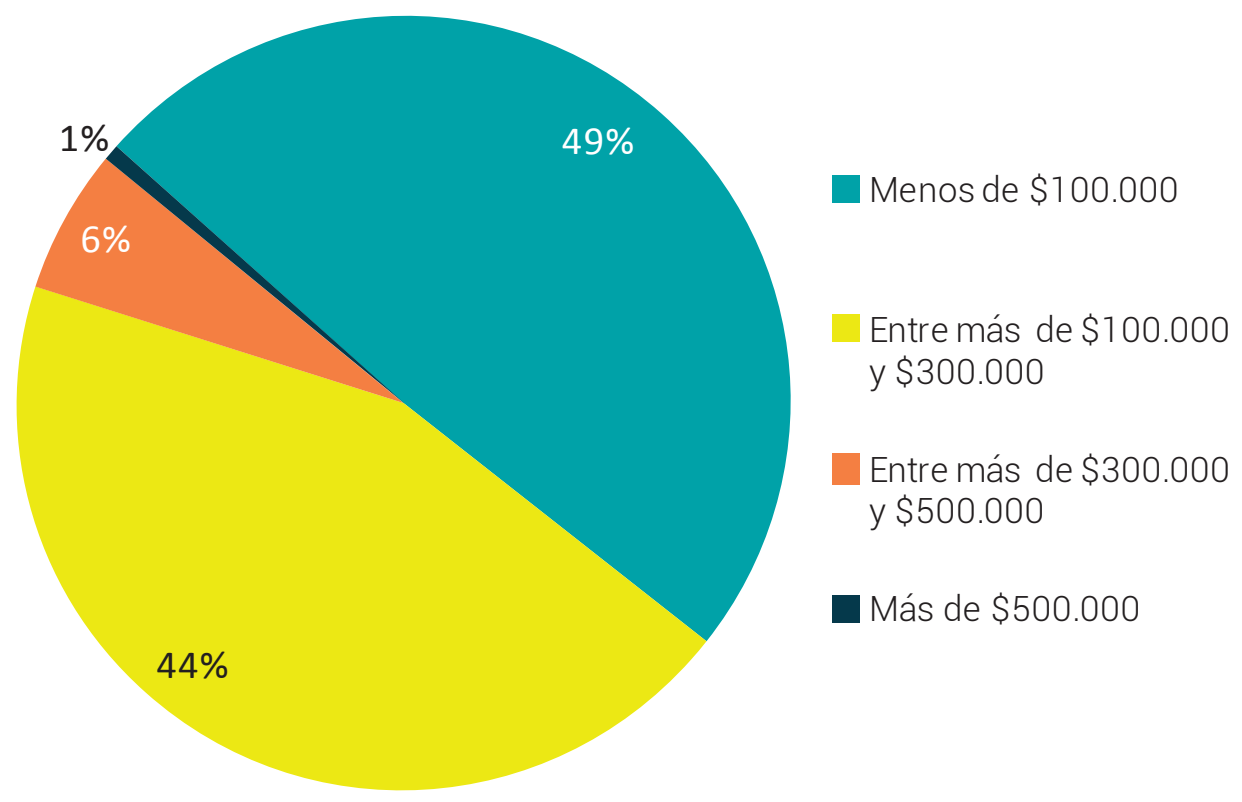

Figura 8. ¿Cuánto invierte mensualmente en productos agroecológicos? Fuente: elaboración propia

Según el DANE (2018), a nivel nacional cada hogar gasta aproximadamente \$308 000 en alimentos y bebidas no alcohólicas, por lo que un $49 \%$ de los encuestados estarían gastando el equivalente al $32 \%$ de este gasto en alimentos y bebidas agroecológicas, y un $44 \%$, el equivalente a un $97 \%$ de este gasto en alimentos y bebidas agroecológicas, si bien en los mercados tipo feria y en Agrosolidaria Engativá se venden, además de alimentos, otros productos. Esto deja en evidencia una gran brecha para alcanzar a suministrar toda la canasta básica de alimentos y bebidas, por parte de la producción agroecológica, si bien muchos consumidores se limitan a comprar las categorías de su preferencia (cereales, frutas y verduras) y no exploran otras, lo cual puede deberse a aspectos educativos relacionados a la calidad de estas diferentes categorías, como el tener o no registro sanitario, o el ser o no una marca reconocida. 
Los resultados de las respuestas tanto de ingresos como de gasto en los mercados pudieron haberse visto afectados por el sector donde se encuentran ubicados algunos mercados: Mercado Agroecológico Campesino del Virrey y Hub en estratos 5 y 6; Mercado Agroecológico Tierra Viva en estratos 3 y 4 de Teusaquillo; Feria Agroecológica UNIMINUTO en estratos 2 y 3; ya que los mercados a domicilio entregan en toda la ciudad. Esta distribución de los integrantes de la RMABR, abarcando casi todos los estratos socioeconómicos, salvo el 1, contradice la idea de que estos mercados están solo en altos estratos (Escobar-Moreno, Gil, y Restrepo, 2015).

\section{Disponibilidad de pagar un sobreprecio}

La pregunta 16 consultó la disponibilidad de los encuestados para pagar un sobreprecio por los productos agroecológicos, los resultados se presentan en la figura 9.

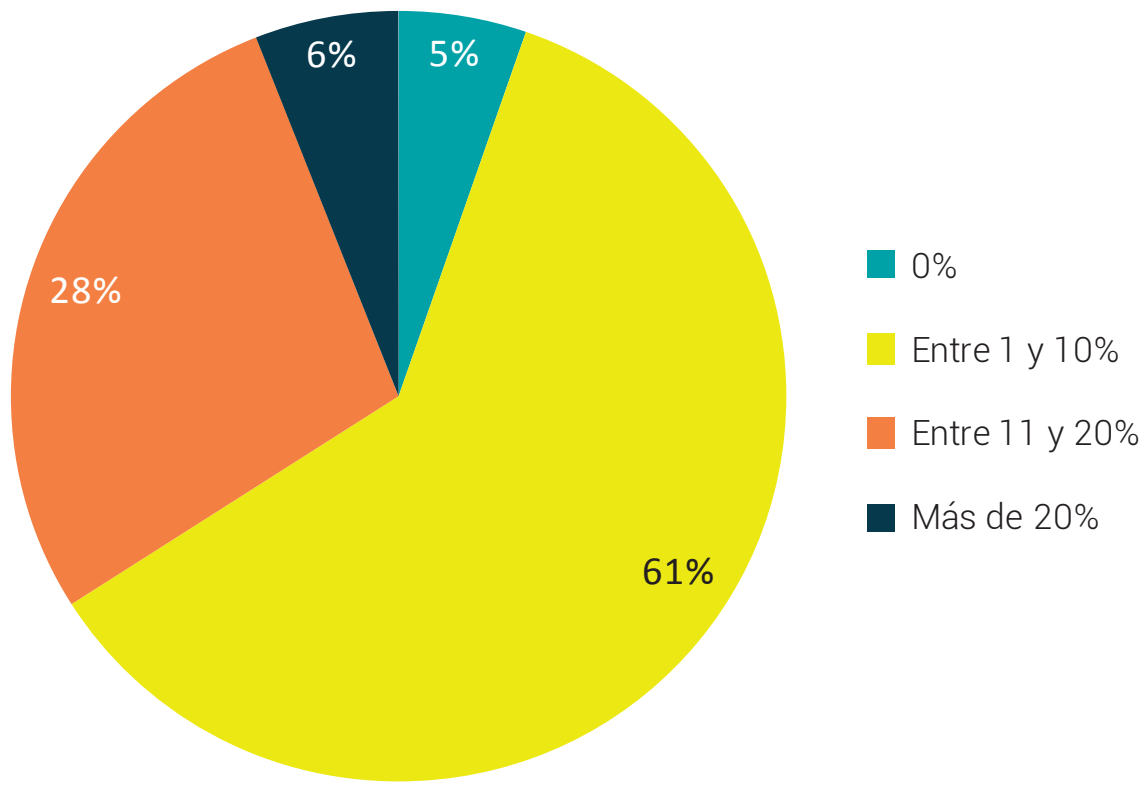

Figura 9. Sobreprecio dispuesto a pagar por productos agroecológicos. Fuente: elaboración propia

Estos resultados son similares a los de investigaciones realizadas en España (Ipsos Insight, 2008), en la FAU (Chaparro y Cortés, 2016), y en Rumania (Vietoris, y otros, 2016), donde el mayor porcentaje de los encuestados estaba dispuesto a pagar el 10 \% como sobreprecio, aunque en Serbia (Kranjac, Vapa-Tankosić, y Knežević, 2017) aumenta este sobreprecio hasta el 20 \%, mayoritariamente. Estos resultados son similares a los de Escobar-Moreno, Gil, y Restrepo (2015), en Antioquia, quienes 
hallaron que solo un $10 \%$ no estaría dispuesto a pagar un sobreprecio, aunque en esta investigación esta proporción es de solo un 5 \%. En el estudio de Vargas y Valencia (2015) con mujeres bogotanas, el 41 \% esta dispuesto a pagar hasta un $10 \%$ y el $41 \%$ entre 11 y 20 \% más. La causa de la disposición a pagar, parece ser la percepción de una oferta de valor superior y de "justicia", a pesar de lo cual, este $10 \%$ de sobreprecio mayoritario no corresponde al precio del mercado, que es muy superior.

Según Rödiger y Hamm (2015) en una investigacion sobre cómo afectan los precios de los productos orgánicos el comportamiento del consumidor, encontraron que en todos los estudios una gran parte de consumidores estaban dispuestos a pagar un sobreprecio en los productos orgánicos, pero esa disposicion de pago diferia por categoría de productos, tambien concluyen que los consumidores más habituales hacia los alimentos orgánicos tuvieron una mayor disposicion de pagar un sobreprecio por productos orgánicos que aquellos con compras ocasionales.

\section{Cómo identifican un producto agroecológico los consumidores}

La opinión de los encuestados sobre cómo identifican un producto agroecológico incluye, para el $47 \%$, el aspecto -color, olor, forma, tamaño, sabor, entre otros-, para el 29 \% el mercado, para el $13 \%$ el sello y etiqueta, para el $7 \%$ la etiqueta, para el $3 \%$ la confianza en el productor y para el 1 \% un certificado legal. Una persona no entendió la pregunta.

Es sorprendente la proporción de encuestados que creen identificar un producto agroecológico por su aspecto, pues este no depende solo de su calidad agroecológica, sino de aspectos relacionados a la nutrición del cultivo o animal, entre otros (Raigón, 2008). Según Gentile y Rodríguez (2002), la mayoría de los consumidores (60 \%) identifican un producto orgánico por la marca, el sello de certificación o la etiqueta de orgánico, mientras el restante $40 \%$ lo identifican por la confianza en el productor. En este estudio, resalta en positivo la confianza que generan los mercados, el sello, la etiqueta y los productores, aunque se evidencia, a su vez, el poco conocimiento que tienen los consumidores del Sistema Participativo de Garantía de la RMABR (Chaparro y Naranjo, 2018).

En Colombia, la legislación en materia de producción ecológica incluye: Resolución 0148 de 2004 MADR (sello ecológico), Resolución 00036 de 2007 (modifica la anterior), Resolución 187 de 2006 (producción ecológica) y su reglamento, Resolución 199 de 2016 (modifica la anterior), que han determinado que la identificación de un producto orgánico tiene lugar por el sello que emite la certificadora 
respectiva, al que se suma el sello de alimento ecológico del Ministerio de Agricultura y Desarrollo Rural MADR. De otro lado, la forma en que la RMABR garantiza a los consumidores que los productos que consumen son de origen agroecológico, es por medio de un Sistema Participativo de Garantía (SPG). El SPG fue reconocido ante el MADR como mecanismo válido de certificación agroecológica por la Resolución 464 de 2017 (Ministerio de Agricultura y Desarrollo Rural - MADR, 2017).

En Andalucía ya son muchas las tiendas y mercados que están ofertando productos ecológicos, por lo que los compradores los identifican principalmente por el sello en el envase, aunque para algunos compradores la garantía es el establecimiento, o porque así lo indica el productor, o por encontrarse en la sección específica de ecológicos (Insight, 2008). Este resultado en parte se explica por la norma que rige la producción y etiquetado de productos orgánicos en España (Reglamento UE 2018/848 del Parlamento Europeo y del Consejo de 30 de mayo de 2018).

\section{Frecuencia de compra}

Respecto a cuál es la frecuencia más conveniente para hacer las compras, las respuestas se presentan en la figura 10. El mercado tipo feria es más agradable para algunas personas por que pueden ir en familia a disfrutar de las conversaciones con los productores.

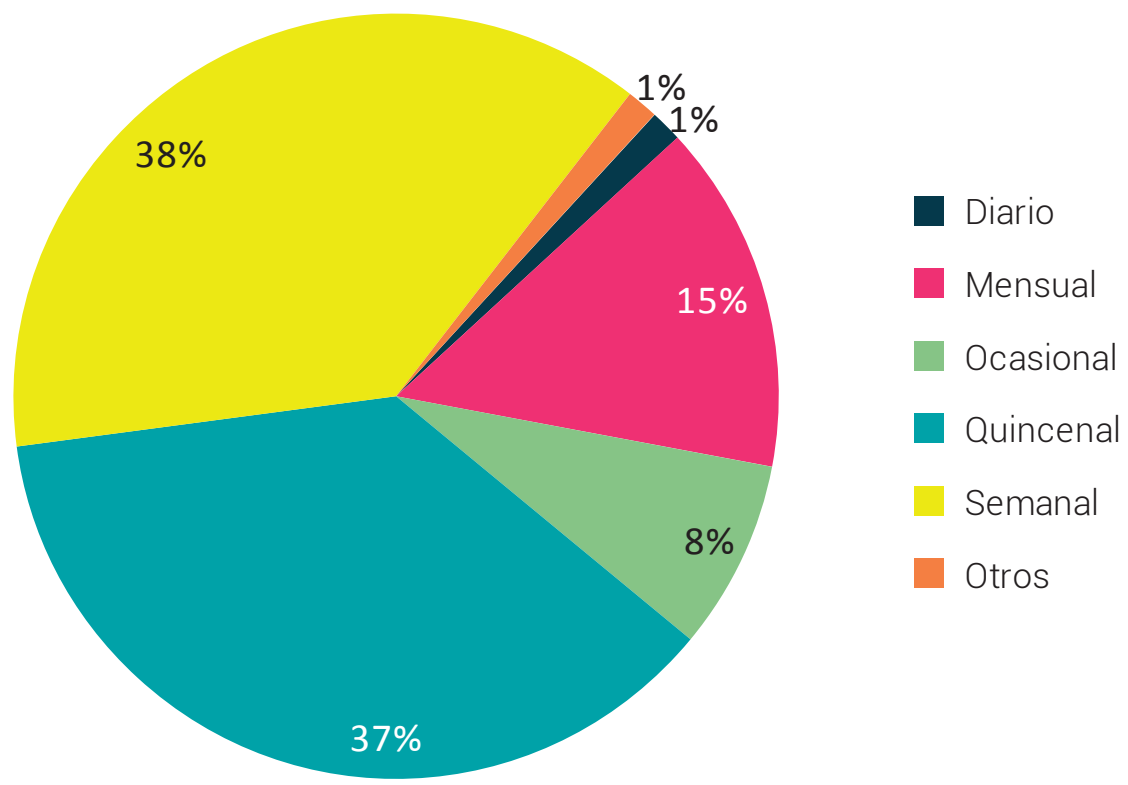

Figura 10. Frecuencia más conveniente para hacer las compras.

Fuente: elaboración propia 
Siendo las frecuencias preferidas por los encuestados la semanal y la quincenal, esto corresponde a la oferta de la mayoría de los mercados - cuatro mercados a domicilio ofertan semanalmente y dos mercados tipo feria ofertan semanal y quincenalmente cada uno-. La tercera frecuencia preferida es mensual, la cual corresponde a la FAU. El quinto mercado a domicilio oferta sus productos dos veces por semana, lo cual podría corresponder a las respuestas de ocasional, diario y otros. Estas frecuencias de los mercados se han ido decantando gracias a la experiencia de los mercados y a la solicitud expresa de los consumidores.

En Andalucía, la frecuencia preferida de compra de los productos analizados - carne, frutas, verduras, leche, pan, huevos, aceite y yogurt- es varias veces a la semana, lo que difiere en gran medida de los resultados de este estudio, y justifica que en España haya diversidad de mercados tipo tienda para productos ecológicos (Ipsos Insight, 2008). En Serbia, el 40,5 \% prefieren comprar una vez por mes, mientras el 39,3\% cada quince días y el 12,9 \% todos los días (Kranjac, Vapa-Tankosić, y Knežević, 2017). Se presume que estas diferencias radiquen en aspectos como el tamaño y demanda de los hogares, la cercanía de los puntos de venta junto con la movilidad de la ciudad, o la facilidad de acceder a domicilios - en cuyo caso las fechas y horarios deben ser cómodos-.

\section{Medio preferido de comunicación}

Sabiendo que en el presente el mundo gira en torno a las nuevas tecnologías para el almacenamiento, recuperación, proceso y comunicación de la información (TIC), (Belloch, 2012) es muy importante saber cuál es el mejor medio para que los mercados de la RMABR puedan comunicarse con los consumidores, en este orden de ideas, del total de los encuestados, 70 \% prefieren recibir correos electrónicos con toda la información relacionada acerca de la RMABR, mostrándose interesados por saber de las fechas, direcciones y horarios de cada mercado, eventos especiales, promoción de productos y otros. El segundo medio de comunicación preferido por el $17 \%$ es WhatsApp, y en tercer lugar por Facebook $6 \%$, por la página web $6 \%$, mientras al $1 \%$ les gustaría más por llamada.

En Bogotá las redes que más se usan son WhatsApp y Facebook, con un $89.4 \%$ y un $86.7 \%$, respectivamente (El Tiempo, 2018), lo que coincide con el estudio de Escobar-Moreno, Gil, y Restrepo (2015), por lo que serían los medios que la RMABR podría utilizar para divulgar la publicidad de los mercados, sin embargo, esta investigación arroja resultados diferentes, esto, porque a los consumidores les es más fácil recibir la información completa y detallada por correo electrónico. 


\section{Tendencias de la compra de productos agroecológicos y propuestas de los consumidores}

Sobre la pregunta ¿qué desearía en el futuro respecto a sus compras de productos agroecológicos? El 64 \% respondió que quisieran comprar productos con mayor constancia. Para el 12 \% es más interesante comprar productos que antes no compraban, hasta llegar al punto de reemplazar por completo todas las compras, esto desde luego en la medida que la RMABR tenga más variedad de productos que ofertar. Por otra parte, el $11 \%$ afirma que les gustaría empezar a comprar en varios mercados a la vez; el 9 \% quisiera comprar más por cada compra que hacen. El $5 \%$ restante pide más variedad en las canastas cerradas, ya compra todo lo que necesita, no ha tenido tiempo para volver a comprar, o no propone cambios.

Las tendencias identificadas en este estudio coinciden con los hallazgos de Ipsos Insight (2008), donde la diversidad y la frecuencia de oferta son las principales expectativas de los clientes. De otro lado, hay que tener en cuenta, que el estudio realizado por Gentile y Rodríguez (2002) indica que a mayor nivel de ingreso, mayor es la cantidad y la variedad de alimentos orgánicos adquiridos.

Complementariamente, el 36 \% de los consumidores de la RMABR (53 personas) propone aumentar la frecuencia de oferta o entrega; reducir los precios en los productos más consumidos o hacer promociones; más flexibilidad en la escogencia de los productos para evitar el desperdicio de alimentos que no se consumen. De esas 53 personas, 20 combinan la respuesta con mejorar los medios y la frecuencia de comunicación, así como la información difundida, otras 14 personas la combinan con ofertar productos agroecológicos que antes no se ofertaban. El 22 \% propone mejorar los medios y la frecuencia de comunicación, así como la información difundida, y otro $22 \%$ ofertar productos agroecológicos que antes no se ofertaban, el $10 \%$ recomienda mejorar la calidad de los productos -tamaño, forma, presentación, entre otros-, el $7 \%$ reducir el precio, y el restante $3 \%$ propone mejorar la puntualidad en la entrega de los domicilios, hacer más publicidad sobre la calidad de los productos y sus beneficios, mejorar la distribución de los mercados agroecológicos en ciertas zonas de la ciudad, mejorar la calidad de los productos -tamaño, forma, presentación, entre otros, sobre todo en frutas y verduras, aunque ha mejorado todavía falta-, y hacer más asequibles los precios.

\section{Otros mercados en que participan los encuestados}

Por último, se preguntó a los encuestados ¿en qué otros mercados realizan sus compras de productos convencionales o agroecológicos, que productos adquiere allí y 
por qué? Fue una pregunta abierta que respondieron el $83 \%$ (123 personas), de las cuales el $21 \%$ dice comprar en supermercados o hipermercados los productos que no consigue en los mercados de la RMABR; otro $20 \%$ hace las compras en ferias que no están vinculadas con la RMABR, o directamente a productores, en panaderías especializadas, o en tiendas orgánicas o ecológicas; el 16 \% dice comprar en supermercados y en tiendas de barrio a la vez; el $15 \%$ solo compra en tiendas de barrio; el $7 \%$ hace sus compras en tiendas de barrio y ferias/plazas de mercado; el restante 21 \% compra en diferentes puntos como supermercado, tiendas de barrio, ferias/ plazas y a domicilio.

Los productos que adquieren en estos mercados son leche, pan, aceites, maní, snacks, sal, chocolate, productos sin gluten, pan hecho con masa madre, verduras, frutas, avena, peto, canela, clavos, nuez, almendra, centeno, granos, arroz, cereales, yuca, plátano, rugula, aromáticas, carne de res, jamón de pavo, pescados frescos y productos de aseo personal y para el hogar - detergente para la ropa y loza, crema dental, cremas cosméticas - y ropa. Los motivos por los que se visitan estos mercados son por su cercanía, precios bajos, porque no los ofrece la RMABR, hay más variedad de productos, posibilidad de reenvasar los jabones y así no usar más plástico, compra en grandes cantidades, evitar costos de transporte y atención toda la semana.

Como en este estudio, para Henryks, Cookse, y Wright (2014), en Australia el $1 \%$ y en Estados Unidos el 4 \% compra productos orgánicos, pero la mayoría de ellos compra solo ocasionalmente productos como carne, por motivos de precio y disponibilidad.

\section{Conclusiones}

Si bien se espera realizar un nuevo estudio en la RMABR con una muestra superior, los resultados presentados a continuación permitirán avanzar en la construcción de una estrategia de comunicación, educación y mercadeo para el consumo sostenible:

- Primer objetivo específico: caracterizar el perfil de los consumidores de la RMABR mediante la aplicación de una encuesta, para determinar quiénes y porqué participan de los mercados agroecológicos -elementos de la demanda que inciden en la compra-.

El perfil del consumidor que participa en los mercados de la RMABR es: mayoritariamente mujeres adultas jóvenes, universitarias, colombianas, siendo estos los factores sociodemográficos más determinantes. Mientras los ingresos entre uno y dos o mayor a cuatro SMMLV; ocupaciones como 
ciencias sociales, naturales y educación; además de hogares formados por dos o tres personas, son características importantes, pero no igualmente determinantes, lo cual es sorprendente, sobre todo en lo referente a los ingresos, que determinan en gran medida el poder adquisitivo del consumidor.

- Segundo objetivo específico: caracterizar el consumo de productos agroecológicos en los consumidores de la RMABR, mediante la aplicación de una encuesta, para determinar qué elementos de la oferta inciden en la compra.

La calidad agroecológica de los productos es el factor que más incide en la compra (78\%), ya que su consumo beneficia la salud (73\%), si bien es interesante que también resaltan el aporte a la protección ambiental, la calidad de los productos, el aporte a un sistema social más justo y la producción local. La principal desmotivación de compra es el precio (36\%), a pesar de lo cual están dispuestos a pagar, un 61 \% de los encuestados, hasta un $10 \%$ más.

Los productos que más compran son cereales, frutas y verduras, gastando un $49 \%$ menos de $\$ 100000$ y un $44 \%$ entre $\$ 100000$ y $\$ 300000$ por mes, lo que permite evidenciar una demanda local nada despreciable.

Los consumidores de la RMABR prefieren comprar directamente al productor o en ferias, recibir información por correo electrónico, comprar semanal o quincenalmente, quieren encontrar productos diferentes a alimentos y alimentos que comúnmente no se encuentran y asegurar la oferta de los básicos - cebolla, yogurt y otros-.

- Tercer objetivo específico: determinar cuál es la tendencia de consumo de productos agroecológicos por parte de los consumidores de la RMABR, mediante la aplicación de una encuesta, para establecer que esperan de estos mercados agroecológicos.

La mayoría esperan comprar productos que en la actualidad no compran, y proponen aumentar la frecuencia de oferta, ser flexibles en la escogencia de productos - canasta abierta-, mejorar la puntualidad de domicilios, calidad de productos -frutas y verduras-, comunicación y precio. 


\section{Recomendaciones}

Para reducir la barrera del precio es necesario, por un lado, compartir información con los consumidores sobre los costos de producción y los beneficios de la producción y el consumo de productos agroecológicos, desde el concepto de externalidades. Por otro lado, bajar los precios en los casos en que la escala de producción se pueda aumentar.

Para aumentar la cantidad y frecuencia de las compras por consumidor, se requiere mejorar la oferta - diversidad de productos alimenticios y no alimenticios, continuidad-, la calidad - productos frescos especialmente-, la logística -frecuencia, ubicación de los mercados, presentaciones-, y la comunicación -fechas, ubicación, logística, Sistema Participativo de Garantías, beneficios en salud, ambientales y sociales-. En el tema de logística debería evaluarse el mercado tipo tienda.

\section{Referencias}

Andrade, D., y Flores, M. (2008). Consumo de alimentos orgánicos/agroecológicos en los hogares ecuatorianos. Quito, Ecuador: Veco.

Arroyave, C. (2015). Tendencias de producción y consumo ecológico en Antioquia. Medellín, Colombia: Universidad de Medellín Maestría en Mercadeo .

Aschemann-Witzel, J., and Zielke, S. (2015). Can't Buy Me Green? A Review of Consumer Perceptions of and Behavior Toward the Price of Organic Food. 1-41.

Astier, M., Masera, O., y Galván - Miyoshi, Y. (2008). Evaluación de sustentabilidad. Un enfoque dinámico y multidimencional. Valencia, España: SEAE/CIGA/ECOSUR/CIECO /UNAM/GIRA/ Mundiprensa /Fundación Instituto de.

Ávila-Romero, A. (2018). Hacia un diálogo de alternativas entre la economía solidaria y la economía social: el buen vivir como horizonte descolonial. Cooperativismo y Desarrollo, 25(112). doi: https://doi.org/10.16925/co.v25i112.2033, 78-92.

Borrás, V. (2007). Las desigualdades en el consumo a través del género.

Ceccon, E. (2008). La revolución verde tragedia en dos actos. Ciencias, 1(91), 21-29.

Chaparro, A., y Calle, A. (2017). Peasant Economy Sustainability in Peasant Markets, Colombia. Agroecology and Sustainable Food Systems, 41(2), 204-225. 
Chaparro, A., y Naranjo, S. (2018). Cartilla. Sistema Participativo de Garantías. Red de Mercados Agroecológicos de Bogotá Región. Bogotá, Colombia: RMABR.

Chaparro-Africano, A. M. (2019). Toward generating sustainability indicators for agroecological markets. Agroecology and sustainable food systems, 43(1). doi: 10.1080/21683565.2019.1566192, 40-66.

Codex Alimentarius, y FAO. (2005). Alimentos producidos orgánicamente, segunda edición. Roma: FAO.

Daly, H. (1991). Elements of environmental macroeconomics. En R. Costanza, Ecological Economics:the Science and Management of Sustainability. (pp. 32-46). New York: Columbia University Press.

DANE. (2010). Boletín Censo general 2005. Bogotá, Colombia.

DANE. (2018). Encuesta Nacional de Presupuestos de los Hogares (ENPH). Bogotá, Colombia.

EcoLogical. (2018). El sector ecológico en España 2018. España: EcoLogical.

El Tiempo. (21 de 03 de 2018). El Tiempo. Recuperado de https://www.eltiempo.com/colombia/ otras-ciudades/conozca-cuales-son-las-redes-sociales-que-mas-usan-en-su-region-196158

El Tiempo. (16 de 02 de 2018). El Tiempo. Recuperado de https://www.eltiempo.com/bogota/ razones-por-las-que-el-trafico-en-bogota-es-caotico-183678

Escobar-Moreno, N., Gil, A., y Restrepo, A. (2015). Caracterización preliminar del consumidor verde antioqueño: El caso de los consumidores del Valle de Aburrá. Revista de la escuela de administración de negocios, 92-107.

Expansión. (2016). Expansión. Recuperado de http://www.expansion.com/emprendedores-empleo/empleo/2016/11/09/58231dae468aebc1048b46a9.html

FENALCE. (2018). FENALCE. Recuperado de http://www.fenalce.org/alfa/dat_particular/ar/ar_66 896_q_APR_2018_B__Noviembre.pdf

FIBL e IFOAM - Organics International. (2019). The world of organic agriculture. Statistics and emerging trends 2019. Suiza: IFOAM. Recuperado de http://www.organic-world.net/yearbook/ yearbook-2017.html 
Gentile, N., y Rodríguez, E. (2002). El mercado argentino de los alimentos orgánicos. Faces, 7(13), 25-41.

Henryks, J., Cookse, R., and Wright, V. (2014). Organic Food at the Point of Purchase: Understanding Inconsistency in Consumer Choice Patterns. Journal of Food Products Marketing, 20(5), 452-475.

Herrera, C. (2008). Las decisiones de consumo de la mujer en Colombia. Málaga: Observatorio de la Economía Latinoamericana. Recuperado de http://www.eumed.net/cursecon/ecolat/co/08/ chm4.htm

Higuchi, A. (2015). Characteristics of Consumers of Organic Products and the Increase in the Supply of These Products in Metropolitan Lima, Peru. Centro de Investigación de la Universidad del Pacífico, 57-89.

Hinton, E., and Godman, M. (2009). Sustainable consumption: developments, considerations and new directions. En M. R. Redclift, and G. Woodgate, The International Handbook of Environmental Sociology, (Second Edition), (pp. 245-261). London: Edward Elgar .

Hosseinnezhad, F. (2017). Women and the Environment: Ecofeministic Approach to Environmental Attitudes and. European Journal of Sustainable Development Research, 1(1), 4, 1-7.

Ipsos Insight. (2008). Consumo de alimentosecológicosen Andalucía. Andalucía: Junta de Andalucía.

Kranjac, M., Vapa-Tankosić, J., and Knežević, M. (2017). Profile of organic consumers. Economics of Agriculture, 64(2), 497-514.

Krishna, R., and Balasubramanian, P. (2018). The Significance of Factors Influencing Consumer Behaviour towards Organic Food Products in Kochi. International Journal of Pure and Applied Mathematics,119(12). Available: http://www.ijpam.eu Special Issue, 2641-2665.

Kröger, M., and Schäfer, M. (2014). Between Ideals and Reality: Development and Implementation of Fairness Standards in the Organic Food Sector. Journal of Agricultural and Environmental Ethics, 43-63.

León, L. (2017). Hábitos, estilos de vida, y prácticas de consumo de alimentos saludables en jóvenes universitarios de Bogotá. Bogotá: Universidad Santo Tomás.

León-Sicard, T., Sánchez de Prager, M., Rojas, L. J., Ortiz, J. C., Bermúdez, J. A., Acevedo Osorio, A., y Angarita Leiton, A. (2015). Hacia una historia de la agroecología en Colombia. Agroecología, 10(2), 39-53. 
Maldonado, B., Rivas, L., Molina, D., y Flores, J. (2007). Análisis de los modelos del marketing ambiental. Universidad Empresa (Colombia), 6(12), 20-38.

Martín, J. F. (2005). Los factores definitorios de los grandes grupos de edad de la población: tipos, subgrupos y umbrales. Revista electrónica de geografía y ciencias sociales, IX(190).

Martínez, C. (2016). Consumo de alimentos orgánicos en Colombia: una cultura. Especialización en Alta Gerencia. Cajicá: Universidad Militar Nueva Granada.

Ministerio de Agricultura y Desarrollo Rural - MADR. (2006). Resolución 187. Bogotá: MADR.

Ministerio de Agricultura y Desarrollo Rural - MADR. (2017). Resolución 464. Bogotá: Ministerio de Agricultura y Desarrollo Rural.

Ministerio de Agricultura y Desarrollo Rural. (2018). Ministerio de Agricultura y Desarrollo Rural. Recuperado de https://www.minagricultura.gov.co/tramites-servicios/Documents/Lista_ de_Operadores_Ecologicos_141218.pdf

Ministerio de Ambiente y Desarrollo Sostenible. (2018). Resolución 1407 de 2018. Ministerio de Ambiente y Desarrollo Sostenible: Bogotá.

Muhammad, S., Fathelrahman, E., and Ullah, R. (2016). The Significance of Consumer's Awareness about Organic Food Products in the United Arab Emirates. Department of Agribusiness and Consumer Sciences, College of Food and Agriculture, United Arab Emirates University.

Ortiz, D., y Florez, M. (2008). Consumo de productos orgánicos/agroecológicos en los hogares ecuatorianos. Ecuador: VECO- Ecuador.

Prada, A. (Agosto de 2017). Consumo agroecológico en Colombia ¿Quiénes se están alimentando sano en el país?

Raigón, M. (2008). Alimentos ecológicos calidad y salud. Andalucia, España: JUNTA DE ANDALUCíA. Consejería de Agricultura y Pesca. Sociedad Española de Agricultura Ecológica (SEAE).

Restrepo, J., Borja, E., Muñoz, O., y Restrepo, D. (2015). Producción orgánica y su impacto en el desarrollo economico del sector rural Colombiano. Agora, Revista virtual de estudiantes, 2., 57-66.

RMABR. (2019). Red de mercados agroecológogicos Bogotá región. Recuperado de http://redmercadosagroecologicosbogota.co/home/participa/ 
Rödiger, M., and Hamm, U. (2015). How are organic food prices affecting consumer behaviour? A review. ELSEVIER.

Rosset, P., y Martínez, M. (2016). Agroecología, territorio, recampesinización y movimientos sociales. Estudios Sociales. Revista de investigación científica, 25(47), 275-299.

Sagástegui, D. (2004). Una apuesta por la cultura: el aprendizaje situado. Revista Electrónica Sinéctica, 24, 30-39.

Sánchez, J. (2017). Mercado de productos agrícolas ecológicos en Colombia. Suma de negocios, $8,156-163$.

SENA. (2017). Clasificación nacional de ocupaciones Versión 2017. Bogotá: SENA.

Sevilla-Guzmán, E. (2006). De la sociología rural a la agroecología. Madrid: Icaria.

Storstad, O., y Bjørkhaug, H. (2003). Foundations of production and consumption of organic food in Norway: Norway: Common attitudes among farmers and consumers? Agriculture and Human Values, 20(2), 151-163.

Vargas, N., y Valencia, M. (2015). Caracterización del perfil de compra de productos verdes del género femenino en la ciudad de Bogotá. Bogotá: Colegio de Estudios Superiores de Administración -CESA Maestría Dirección de Marketing.

Vietoris, V., Kozelová, D., Mellen, M., Chreneková, M., Potclan, J., Fikselová, M., Horská, E. (2016). Analysis of Consumer Preferences at Organic Food Purchase in Romania. Pol. J. Food Nutr. Sci., 66(2). doi: 10.1515/pjfns-2015-0028, 139-146. 